\title{
Antigen gene transfer to cultured human dendritic cells using recombinant avipoxvirus vectors
}

\author{
M. Brown, ${ }^{1}$ D. H. Davies, ${ }^{2}$ M. A. Skinner, ${ }^{3}$ G. Bowen, ${ }^{2}$ S. J. Hollingsworth, ${ }^{4}$ G. J. Mufti, ${ }^{4}$ \\ J. R. Arrand, ${ }^{1}$ and S. N. Stacey ${ }^{1}$ \\ ${ }^{1}$ Cancer Research Campaign, Section of Molecular Genetics, Paterson Institute for Cancer Research, Christie \\ Hospital National Health Service Trust, Manchester, United Kingdom; ${ }^{2}$ Division of Life Sciences, Kings \\ College London, London, United Kingdom; ${ }^{3}$ Department of Molecular Biology, Institute for Animal Health, \\ Compton, Newbury, Berkshire, United Kingdom; and ${ }^{4}$ Department of Hematological Medicine, King's \\ College Hospital School of Medicine and Dentistry, London, United Kingdom.
}

\begin{abstract}
Advances in understanding the role of dendritic cells (DCs) as the major antigen (Ag)-presenting cell type of the immune system combined with the recent development of methods for the ex vivo expansion of human DCs have opened the possibility for the transfer of tumor Ags to DCs with a view toward tumor immunotherapy. In this study, we examined the feasibility of Ag transfer to cultured human DCs using the host range-restricted avipoxvirus, fowlpoxvirus (FWPV). FWPV was found to infect and express a lacZ marker gene in a number of mammalian cell lines of fibroblastic, epithelial, and hemopoietic lineage origins. LacZ recombinant FWPV (rFWPV) was found subsequently to infect human DCs that had been cultured ex vivo from peripheral blood monocytes. Using rFWPV containing lacZ under the control of a vaccinia virus (VV) early/late promoter (p7.5K) and a 10 plaque-forming units per cell multiplicity of infection, $>80 \%$ of cells expressed the lacZ marker gene. Quantitative analysis showed that the level of expression continued to rise for 5 days postinfection, at which point the experiments were terminated. Replication-competent recombinant $\mathrm{VV}(\mathrm{rVV})$ was also shown to be capable of transferring the marker gene to primary DC cultures. However, neither rFWPV nor rVV were able to express transgenes under the control of late viral promoters, indicating that both rFWPV and rVV infections are arrested at an early stage in human DCs. Infection of CD83 + DCs by rFWPV was confirmed by double-staining cytochemistry. We conclude that host range-restricted FWPV can be used efficiently to transfer Ag genes to human DCs ex vivo and may have a role in the development of tumor immunotherapy protocols.
\end{abstract}

Key words: Dendritic cells; fowlpoxvirus; transgene; immunotherapy.

$\mathrm{D}$ endritic cells (DCs) are the professional antigen (Ag)-presenting cells (APCs) of the immune system and are crucial for the initiation of cell-mediated immune responses in vivo. ${ }^{1}$ In particular, the ability of DCs to generate a primary $\mathrm{T}$-cell response makes them of particular interest in cancer immunotherapy. ${ }^{2}$ DCs are specialized for Ag uptake, processing, and presentation to naive $\mathrm{T}$ cells by both major histocompatibility complex (MHC) class I- and II-restricted pathways. DCs can be characterized by their distinctive morphology, expression of high levels of MHC class I and II, and high levels of costimulatory molecules such as B7-1, B7-2, intercellular adhesion molecules, leukocyte function-associated Ags, and interleukin-12 (IL-12). ${ }^{3}$

Received January 15, 1998; accepted May 4, 1998.

Address correspondence and reprint requests to Dr. S. N. Stacey, Section of Molecular Genetics, Paterson Institute for Cancer Research, Christie Hospital National Health Service Trust, Manchester M20 9BX, U.K.

(C) 1999 Stockton Press 0929-1903/99/\$12.00/+0
The study of DCs has been hampered because DCs are at very low frequencies in peripheral blood $(<0.1 \%$ of leukocytes). However, methods are now available for the in vitro proliferation and maturation of DC precursors from human donors, using either $\mathrm{CD} 34^{+}$or $\mathrm{CD} 14^{+}$ cells as starting material. ${ }^{4-6}$ These advances have opened up the possibility of transferring specific tumor Ags to DCs in vitro, with a view toward the stimulation of antitumor immune responses by the reinfusion of $\mathrm{Ag}$ loaded DCs. ${ }^{2,7-13}$ When using this method to generate immunity to specific human tumor Ags, it is necessary to obtain high-efficiency transfer of the Ags to DC preparations. Various methods have been used previously to transfer specific tumor Ags to human DCs; these methods include peptide and protein pulsing, ${ }^{9,12,14-16}$ transfection, ${ }^{17,18}$ and virus-mediated gene transfer. ${ }^{19-21} \mathrm{Im}$ provements in these methods would seek to provide high-efficiency transfer of entire $\mathrm{Ag}$ sequences, eliminating the requirement for a detailed knowledge of appropriate T-cell epitopes for each patient. Moreover, endogenous synthesis of Ag by DCs would provide for the 
most efficient $\mathrm{MHC}$ class I-restricted $\mathrm{Ag}$ presentation and cytotoxic T lymphocyte (CTL) generation. ${ }^{21}$

Recombinant poxviruses, such as vaccinia virus (VV), have a long record as effective immunogens for the generation of T-cell immunity in animal models and humans. ${ }^{22}$ These live virus vectors facilitate the intracellular synthesis of recombinant Ag, which allows natural processing and presentation of peptides in an MHC class I-restricted context, appropriate for CTL generation. ${ }^{23}$ Several experimental and candidate anti-human tumor recombinant viruses have been tested, with promising preliminary results. ${ }^{24,25}$ However, there is concern over the use of VV as a tumor immunotherapy vector due to the rates of vaccine-induced skin and central nervous system complications and the potential spread to unvaccinated contacts. ${ }^{26-28}$ These problems are pronounced when adjuvant immunotherapy for cancer is being contemplated, because these patients will often suffer immunosuppression caused by their disease or primary treatment mode. Therefore, lower risk delivery systems are required, which must maintain adequate levels of protection. In addition, animals or humans with preexisting immunity to vaccinia are inhibited in their response to subsequent immunizations with a recombinant $\mathrm{VV}(\mathrm{rVV}) \cdot{ }^{29,30}$ Although it is unlikely that smallpox vaccination will ever be required again, the use of rVVs as vaccines may increase in the future. Therefore, it is advantageous to develop alternative poxvirus vector bases that are unlikely to be inhibited by prior immunity to vaccinia.

Members of the avipoxviruses family, such as fowlpoxvirus (FWPV), are naturally host range-restricted to avian cells. However FWPV has been shown to be capable of infecting mammalian cells, resulting in a nonproductive infection with early and, in some cases, late gene expression. ${ }^{31,32}$ This has led to avipoxviruses being used as replication-defective recombinant vaccines in humans ${ }^{33-35}$ and has led to the development of candidate tumor immunotherapy avipoxvirus vectors. ${ }^{36,37}$

We have shown previously that human peripheral blood low-density cell preparations that are enriched for DCs can act as powerful APCs for the generation of Ag-specific, ex vivo CTL immunity when infected with $\mathrm{rVV}^{38}$ In that study, we used replication-competent VVs, and no attempts were made to expand the DC population in culture. In the present study, we used recombinant FWPV (rFWPV) and replication-competent VVs to try to obtain high-efficiency marker gene transfer to human DCs that had been expanded in culture from peripheral blood. We found that it was possible to transfer genes to the DCs at efficiencies similar to those achieved with B cell lines. With both FWPV and VV, only constructs driven by an early (p7.5K) promoter were capable of expressing the transgene, suggesting that both FWPV and VV are incapable of activating late functions in human DCs. These findings open up possibilities for using host range-restricted poxviruses containing tumor $\mathrm{Ag}$ genes as efficient vectors for the transduction of human DCs for tumor immunotherapy.

\section{MATERIALS AND METHODS}

\section{Cell lines}

Primary chick embryo fibroblasts (CEFs) were prepared as described previously. ${ }^{39}$ The Japanese quail fibrosarcoma cell line QT35 ${ }^{40}$ was grown in 199 medium with $10 \%$ fetal calf serum (FCS). All of the other cell lines used were obtained from the European Type Culture Collection (Porton Down, U.K.) or the American Type Culture Collection (Manassas, Va). P815 mastocytoma, RMA, EL4 lymphoma murine cell lines, and the human B-lymphoblastoid cell line JY were cultured in RPMI 1640 medium with 10\% FCS. HeLa and Swiss-3T3 cells were maintained in Dulbecco's modified Eagle's medium with $10 \%$ FCS. CV-1 monkey kidney cells were grown in minimum essential medium with $10 \%$ FCS.

\section{Recombinant poxviruses}

The Fp9 strain of FWPV was used, and recombinants were based on this strain. rFWPV fpEFL $2^{41}$ contains a VV-derived p7.5K early/late promoter driving a lacZ cassette inserted into the $B g l$ II site of nonessential ORF-1 in the terminal BamHI fragment of FWPV-Fp9. fpEFL $29^{42}$ contains the FWPV p4b late promoter ${ }^{43}$ controlling lacZ inserted into the same locus. FWPV were propagated and titrated on CEFs. For the production of FWPV stocks, CEFs $\left(8 \times 10^{7}\right.$ cells $)$ were inoculated at a multiplicity of 1 plaque-forming unit (PFU)/cell, and the infection was allowed to proceed for 5 days. Cells were scraped up into the medium and lysed by freeze-thawing. Cellular debris was removed by low-speed centrifugation. The medium/ cell lysate was then centrifuged at $40,000 \times g$ for 80 minutes at $4^{\circ} \mathrm{C}$. The virus pellet was resuspended in $2 \mathrm{~mL}$ of $10 \mathrm{mM}$ tris(hydroxymethyl)aminomethane $(\mathrm{pH} 9.0)$, titrated, and stored at $-20^{\circ} \mathrm{C}$. Typical titers were of the order $10^{8} \mathrm{PFU} / \mathrm{mL}$. For infection of mammalian cells, FWPV was diluted in phosphate-buffered saline (PBS) containing $0.5 \%$ bovine serum albumin (BSA) and $0.1 \%$ FCS and was applied to cell cultures at a multiplicity of $10 \mathrm{PFU} / \mathrm{cell}$. The inoculum was removed after 1 hour, and the medium was replaced.

The VV strain WR was used as a wild type and as a base for recombinants. rVV v182 expresses lacZ under the control of the $\mathrm{p} 7.5 \mathrm{~K}$ early/late promoter from an insertion within the TK locus, whereas vAL expresses lacZ under the control of the p11K late promoter inserted into the TK locus. v182 and vAL were constructed and kindly provided by Dr. M. Mackett. VVs were maintained, expanded, and titrated on CV-1 cells as described previously. ${ }^{44}$ Infection of mammalian cells was conducted in the same manner as FWPV.

\section{$\beta$-galactosidase ( $\beta$-gal) assay}

Cells were infected with FWPV or VV and subsequently plated on 96 -well plates at $10^{4}$ cells $/ 100 \mu \mathrm{L} /$ well. At various timepoints, the level of $\beta$-gal was determined by the addition of 50 $\mu \mathrm{L} /$ well of $2.5 \mathrm{mM}$ chlorophenol red $\beta$-D-galactopyranoside (Boehringer Mannheim, Mannheim, Germany) in 2\% sodium dodecyl sulfate, $50 \mathrm{mM} \mathrm{KCl}, 5 \mathrm{mM} \mathrm{MgSO}_{4}$, and $1.3 \% \beta$-mercaptoethanol followed by incubation at $37^{\circ} \mathrm{C}$ for 2 hours. Absorbance was then determined at $590 \mathrm{~nm}$ using an automated microplate reader (Molecular Devices, U.K.). The levels of expression were determined as: $\left(\left[\mathrm{A}_{590}-\mathrm{A}_{590}\right.\right.$ (day $0)] /\left[\mathrm{A}_{590}\right.$ (maximum) $-\mathrm{A}_{590}($ day 0$\left.\left.)\right]\right) \times 100 \%$. For the determination of late promoter usage in some samples, cytosine arabinoside (AraC) was added to a final concentration of $40 \mu \mathrm{g} / \mathrm{mL}$ at 1 hour before infection and was maintained 
throughout the assay. Three separate infections were used for each condition.

\section{Isolation and cultivation of DCS}

DC were cultured according to the method of Romani et al. ${ }^{4}$ Briefly, peripheral blood mononuclear cells (PBMCs) were isolated by Ficoll-Paque density gradient centrifugation, resuspended at $2 \times 10^{6}$ cells $/ \mathrm{mL}$ in Iscove's modified Dulbecco's medium containing $10 \%$ FCS, and distributed to 24 -well plates at $1 \mathrm{~mL} /$ well. After a 2 -hour incubation at $37^{\circ} \mathrm{C}$, the nonadherent cells were removed and the medium was replaced with $1 \mathrm{~mL}$ of complete medium supplemented with 1000 international units (IU)/mL granulocyte-macrophage colony-stimulating factor (GM-CSF) (Sandoz Pharmaceuticals, Basel, Switzerland) and $500 \mathrm{IU} / \mathrm{mL}$ IL-4 (Searle Diagnostics). After 7 days, the resultant population consisted predominantly of cells with a dendritic morphology. These preparations were found to be $>100$-fold more potent stimulators than PBMCs in mixed lymphocyte reactions and were $>10$-fold more potent as APCs in proliferation assays to the recall $\mathrm{Ag}$ tetanus toxoid. ${ }^{45}$

\section{Flow cytometric analysis}

DCs from 7-day GM-CSF/IL-4 cultures were analyzed by flow cytometry using antibodies (Abs) directly conjugated to fluorescein isothiocyanate (FITC) or phycoerythrin (PE). AntiCD2/FITC, -CD3/FITC, -CD4/FITC, -CD8/FITC, -CD14/ FITC, -CD19/PE, -histocompatibility leukocyte Ag (HLA)-A, -HLA-B, -C/FITC, -HLA-DP, -HLA-DQ, and -HLA-DR/PE were purchased from Serotec (Oxford, U.K.). Anti-CD33/PE and -CD34/FITC were purchased from Becton Dickinson (Mountain View, Calif), and anti-CD80/PE was purchased from PharMingen (Cambridge Bioscience, Cambridge, U.K.). Anti-CD83 was kindly provided by Prof. T.F. Tedder (Duke University Medical Center).

\section{Immunofluorescence and light microscopy}

DCs were infected at a multiplicity of $10 \mathrm{PFU} /$ cell for 1 hour with rFWPV or VV. Cells were then washed and replated at $1 \times 10^{6}$ cells/well in six-well plates in Iscove's modified Dulbecco's medium supplemented with $10 \%$ FCS, $1000 \mathrm{IU} / \mathrm{mL}$ GM-CSF, and $500 \mathrm{IU} / \mathrm{mL}$ IL-4. At 48 hours postinfection, cells were stained by the addition of $330 \mu \mathrm{g} / \mathrm{mL}$ 5-bromo-4-chloro3 -indolyl $\beta$-D-galactoside followed by overnight incubation. DCs were washed twice in PBS, $0.2 \%$ sodium azide, and $0.2 \%$ BSA and subsequently incubated with anti-CD83 mAb (HB15; 1:150) for 30 minutes on ice. After washing, FITC-conjugated rabbit anti-mouse secondary Abs were added (Dako, High Wycombe, U.K.; 1:500) followed by incubation on ice for 30 minutes. DCs were then washed three times before fixing in $100 \mu \mathrm{L}$ of $0.5 \%$ paraformaldehyde in PBS, $0.2 \%$ sodium azide, and $0.2 \%$ BSA. A total of $1 \times 10^{5}$ cells were then mounted onto slides by cytospin. $\beta$-gal expression and CD83 staining were then assessed by light and fluorescence microscopy.

\section{RESULTS}

It has been shown previously that FWPV vectors can be used to express foreign genes in mammalian fibroblast and epithelial cell lines. To confirm and extend these observations to lines commonly used as APCs, we used rFWPV containing the lacZ reporter gene under the control of early or late promoters to infect a panel of cell

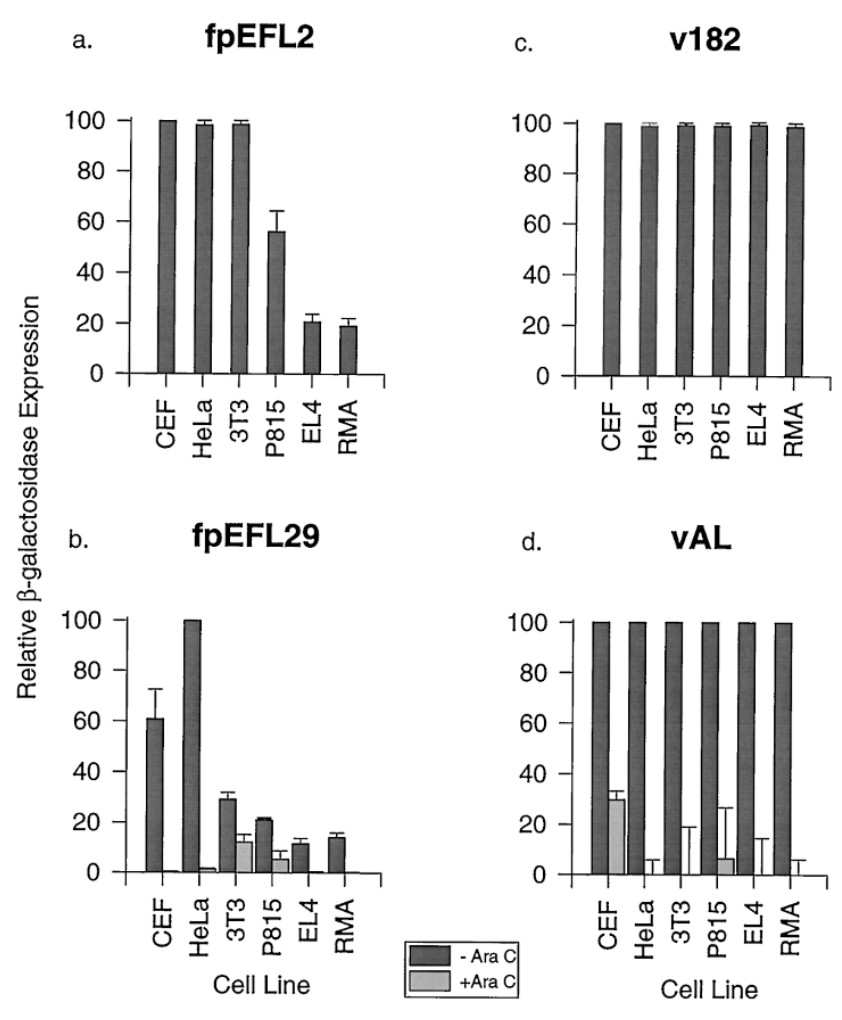

Figure 1. Infection of avian (CEF) and mammalian cell lines (HeLa, Swiss-3T3, P815, EL4, and RMA) with recombinant lacZ poxviruses. Cells were infected with the respective viruses at a multiplicity of infection (MOI) of $10 \mathrm{PFU} / c e l l$, and $\beta$-gal activity was determined at 3 days postinfection. a: Infection with rFWPV fpEFL2, which contains lacZ under the control of the $\mathrm{p} 7.5 \mathrm{~K}$ early/late promoter. $\mathbf{b}$ : Infection with rFWPV fpEFL29, which contains lacZ under the p4b late promoter. Samples are shown with and without the addition of AraC (40 $\mu \mathrm{g} / \mathrm{mL})$ to inhibit viral DNA replication. c: Infection with rVV $\mathrm{v} 182$ containing lacZ under the $\mathrm{p} 7.5 \mathrm{~K}$ promoter. d: Infection with rVV vAL with lacZ under the p11K (late) promoter, with and without the addition of AraC.

lines. The expression of $\beta$-gal was monitored every 24 hours for 5 days. Figure 1a shows the results from a 3-day infection with rFWPV fpEFL2, which contains the lacZ gene under the control of the vaccinia $\mathrm{p} 7.5 \mathrm{~K}$ early/late promoter. High-level expression was observed in the permissive line, in CEFs, and in the nonpermissive lines (HeLa and Swiss-3T3). Expression was seen, although at reduced levels, in the cell lines P815, EL4, and RMA. When rFWPV fpEFL29 (expressing lacZ under the control of a late ( $\mathrm{p} 4 \mathrm{~b}$ ) promoter) was used, late gene expression was observed in CEFs and HeLa cells, with significantly reduced levels produced in 3T3, P815, EL4, and RMA cells (Fig 1b). To confirm that late (postreplicative) gene expression was being observed in these cells, control experiments were conducted in which AraC was added to the infections to prevent viral DNA replication. As shown in Figure 1b, $\beta$-gal expression from fpEFL29 was inhibited by AraC in all cases, confirming that the observed lacZ gene expression was from late promoter activity.

For comparison, similar experiments were conducted 
a.

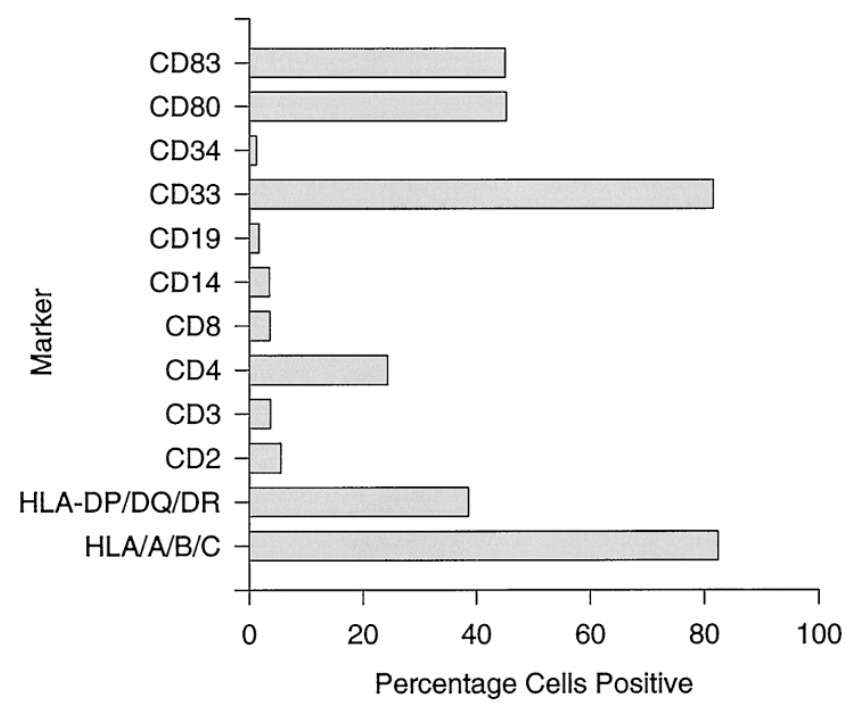

b.

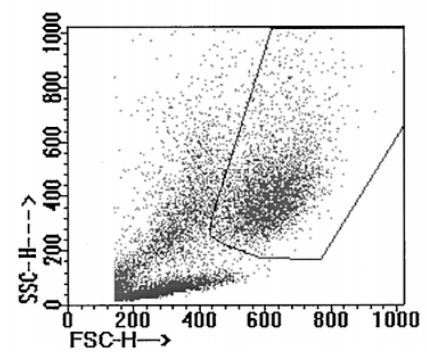

Figure 2. Flow cytometric analysis of DCs cultured from human peripheral blood in the presence of GM-CSF and IL-4 for 7 days. a: Phenotypic analysis using a panel of cell surface markers (HLA-AV B/C, HLA-DP/DQ/DR;,CD2, CD3, CD4, CD8, CD14, CD19, CD33, CD34, CD80, and CD83). Results are displayed as a bar chart depicting the percentage of cells that are positive for each marker. b: Flow cytometric scattergram showing a high forward scatter (FSC-H) and side scatter (SSC-H) profile.

using replication-competent rVV. Using viruses v182 and vAL, with the lacZ gene under the control of an early/late $\mathrm{p} 7.5 \mathrm{~K}$ promoter or the late $\mathrm{p} 11 \mathrm{~K}$ promoter respectively, high-level expression was seen in all lines (Fig 1, c and d). As observed for rFWPV fpEFL29, inhibition of replication with AraC strongly inhibited expression from the $\mathrm{p} 11 \mathrm{k}$ promoter in $\mathrm{vAL}$.

We subsequently sought to determine whether rFWPV could deliver transgenes to cultured human DCs. DCs were isolated and expanded from PBMCs by culture in media supplemented with GM-CSF and IL-4 according to an established procedure. ${ }^{4}$ After 7 days in culture, the population was assessed by flow cytometry. The cells expressed high levels of HLA molecules, adhesion molecules (CD80), and the DC-selective marker CD83, whereas low levels of $\mathrm{T}$ cell $(\mathrm{CD} 2, \mathrm{CD} 3, \mathrm{CD} 4$, and CD8), $\mathrm{B}$ cell (CD19), and natural killer cell (CD2) markers were observed (Fig 2a). DCs are distinguished from
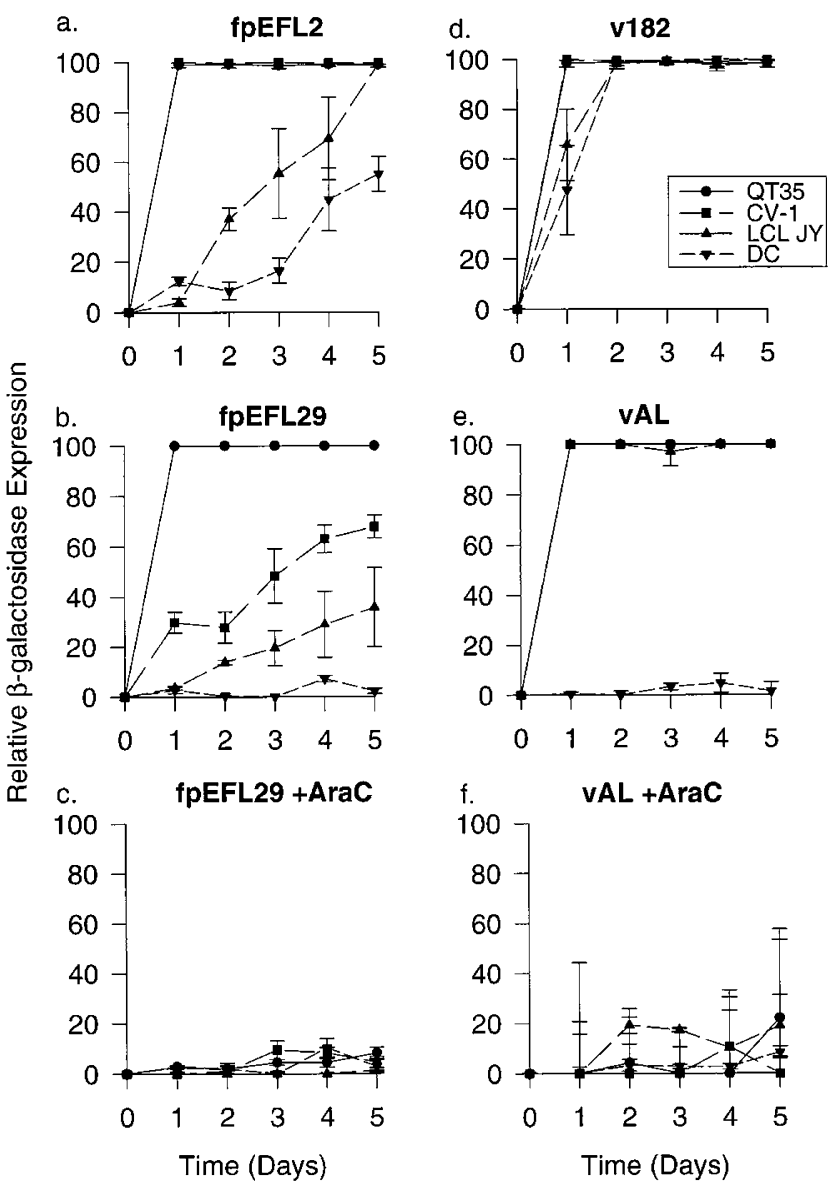

Figure 3. Infection of cultured human DCs and continuous cell lines of avian (QT35) and primate (CV-1 and lymphoblastoid cell line JY) origins. The graphs show time course assays that follow the level of $\beta$-gal expression after infection with either lacZ rFWPV or rVV at an MOI of 10. rFWPV fpEFL2 (a) and rVV v182 (d) both express $\beta$-gal from the vaccinia early/late promoter p7.5K, whereas fpEFL29 (b) and $v A L$ (e) use the native late promoters $p 4 b$ and $p 11 \mathrm{~K}$. The effect of $\operatorname{AraC}(40 \mu \mathrm{g} / \mathrm{mL})$ on the late viral expression from fpEFL29 (c) and $\mathrm{VAL}(\mathbf{f})$ is also shown.

other cell lineages during flow cytometric analysis by their large size and granularity, causing high forward and side scatter, respectively (Fig $2 b$, gated population). The cells were shown to be highly active as APCs in mixed leukocyte reactions and tetanus toxoid reactivation assays. $^{45}$

After 7 days in culture, DC preparations were infected at a multiplicity of $10 \mathrm{PFU} /$ cell with $\mathrm{rFWPV}$ or $\mathrm{rVV}$ viruses containing the lacZ gene, and expression was followed over a period of 5 subsequent days. For comparison, we included a Japanese quail cell line, QT35, which is permissive for FWPV infection; CV-1 monkey kidney cells, which have been shown previously to support FWPV DNA replication and late gene expression but not progeny virus assembly; ${ }^{31}$ and the human B-lymphoblastoid cell line JY. As shown in Figure 3a, $\beta$-gal expression was observed in DCs infected with rFWPV fpEFL2. The amounts increased over the 5-day 
period, suggesting that the $\mathrm{p} 7.5 \mathrm{~K}$ promoter remained active throughout this period. The B cell line JY showed somewhat higher levels of expression, which also rose continually throughout the time period. In comparison, infection of QT35 and CV-1 showed high-level expression within 24 hours, which is in line with the permissive and semipermissive nature of these cell lines. Expression from the FWPV late $\mathrm{p} 4 \mathrm{~b}$ promoter was also examined using rFWPV fpEFL29 (Fig 3b). In this case, only infection of the permissive QT35 line resulted in maximal expression. No late-gene expression was detected in the DCs, and the levels were reduced in CV-1 and JY. To confirm that the $\beta$-gal activity stemmed from late promoter activity, this experiment was also conducted in the presence of AraC. In all cases, no $\beta$-gal activity was seen in the presence of AraC (Fig 3c). We concluded that $\mathrm{rFWPV}$ can infect DCs and express a transgene under the control of an early promoter but not a late promoter. This finding suggests that $\mathrm{rFWPV}$ replication is restricted at a much earlier stage in DCs than in epithelial cell lines such as HeLa and CV-1. Despite this early restriction, it seems that the early $\mathrm{p} 7.5 \mathrm{~K}$ promoter remains active for $\geq 5$ days postinfection. The human $\mathrm{B}$ cell line JY was able to support some rFWPV late gene expression, although the level was reduced compared with early gene expression.

These experiments were repeated using replicationcompetent rVV vectors. As shown in Figure 3d, infection with v182 resulted in a rapid induction of $\beta$-gal synthesis in all cell types, including the DC preparations (Fig 3d). However, when the late promoter construct vAL was used, no expression was observed in DC preparations, whereas high-level, AraC-suppressible expression was observed in all other cell lines (Fig 3, e and f). This observation indicated that the vaccinia $\mathrm{p} 11 \mathrm{~K}$ late promoter is inactive in DCs, whereas it is active in other lines including the human B cell line JY. This suggests that DCs are nonpermissive for VV replication, and that virus infection arrests at an early stage.

Because the DCs were primary cultures from human peripheral blood and may contain contaminating cell types, we sought to correlate the expression of rFWPV with DC phenotypic features. The 7-day DC cultures were infected with rFWPV fpEFL2, and the infection was allowed to proceed for 48 hours. The cells were stained with 5-bromo-4-chloro-3-indolyl $\beta$-D-galactoside and were subsequently transferred to slides by cytospin. Next, cells were stained with an anti-CD83 Ab followed by an FITC-conjugated secondary Ab. The preparations were examined by phase-contrast light microscopy and by ultraviolet fluorescence microscopy. More than $80 \%$ of the cells stained positive for $\beta$-gal. The predominant cell type showed DC morphology (large-phase bright cells with cytoplasmic extensions) (Fig 4, a and b). Immunofluorescence detection showed that cells that were positive for the CD83 marker expressed $\beta$-gal (Fig 4, c and d). We concluded that the rFWPV-vectored lacZ gene was efficiently transferred and expressed in CD83 ${ }^{+}$DCs.

\section{DISCUSSION}

In this article, we examined the feasibility of using host range-restricted poxvirus vectors to transfer tumor Ags to DCs with a view toward the development of an immunotherapy based on this approach. We found that rFWPV could infect and express early but not late genes in DC preparations derived from peripheral blood monocytic lineage precursors. We also found that a replication-competent poxvirus (vaccinia) was incapable of activating late gene expression in DCs, which is in agreement with a recent report. ${ }^{46}$ It has been shown previously that primary macrophages are nonpermissive for VV replication. Infection could occur, with the activation of early and intermediate but not late promoter activity. ${ }^{47}$ These observations suggest that VV replication is restricted in all monocytic lineage cells, including DCs.

We observed early promoter-driven $\beta$-gal expression in rFWPV-infected DCs at levels comparable with those observed in a B-lymphoblastoid cell line. However, lower levels of $\beta$-gal expression were produced by rFWPV compared with $\mathrm{rVV}$, although both viruses used the p7.5K promoter. This difference could be due to reduced p7.5K promoter activity in the FWPV context or to reduced infectivity by FWPV of the DC targets. The observation that $>80 \%$ of cells stained blue for $\beta$-gal in both rFWPV- and rVV-infected DCs suggests that differences in $\mathrm{p} 7.5 \mathrm{~K}$ promoter activities in the different viral contexts could account for this variation in expression levels. However, we cannot yet exclude that rFWPV-infected DCs may contain lower template levels due to reduced infectivity.

The arrest of poxvirus infection in DCs must occur at a very early stage after infection, because no late gene expression is seen at all in either rFWPV- or rVVinfected cells. In the case of FWPV, late gene expression can be observed in other lines that are nevertheless nonpermissive for replication, such as CV-1, HeLa, etc. (Somogyi et $\mathrm{al},{ }^{31}$ and this work). It would seem that FWPV is not inactivated completely early after infection; however, the steady increase in $\beta$-gal activity over the experimental time course suggests that early promoter activity continues for $\geq 5$ days postinfection. It is well known that an inhibition of late gene expression by AraC leads to a prolonged expression of early genes. It is possible that an analogous situation arises when FWPV late gene expression is prevented in the mammalian DC environment.

The observation that only early poxvirus promoters can sponsor expression in DCs has implications for $\mathrm{Ag}$ presentation and vaccine design. It has long been recognized that the generation of T-cell immunity by rVV was dependent upon the expression of the Ag gene from an early rather than a late promoter. ${ }^{48,49}$ The mechanism for this phenomenon was variously suggested to involve poor processing and presentation of Ag late in infection due to MHC class I down-regulation and the inhibition of intracellular proteolysis. ${ }^{50,51}$ However, our observations suggest that poor generation of T-cell immunity by 
a.

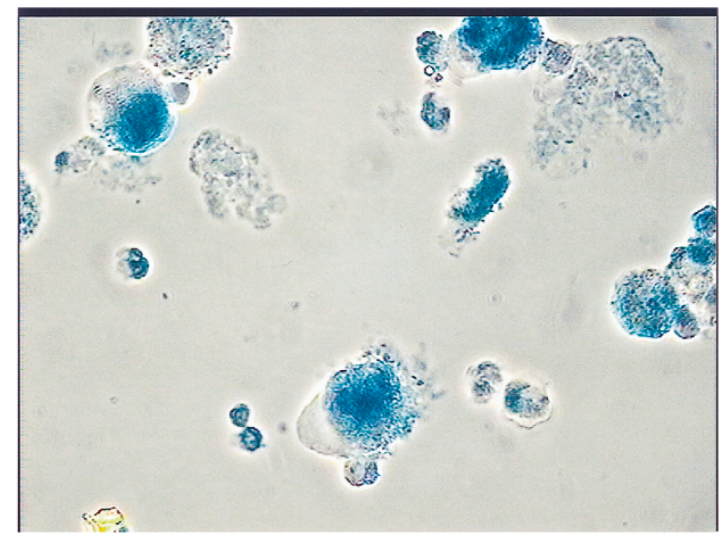

b.

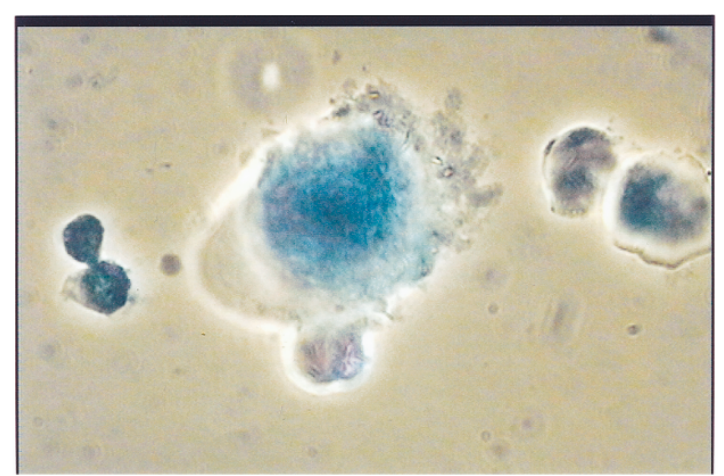

C.

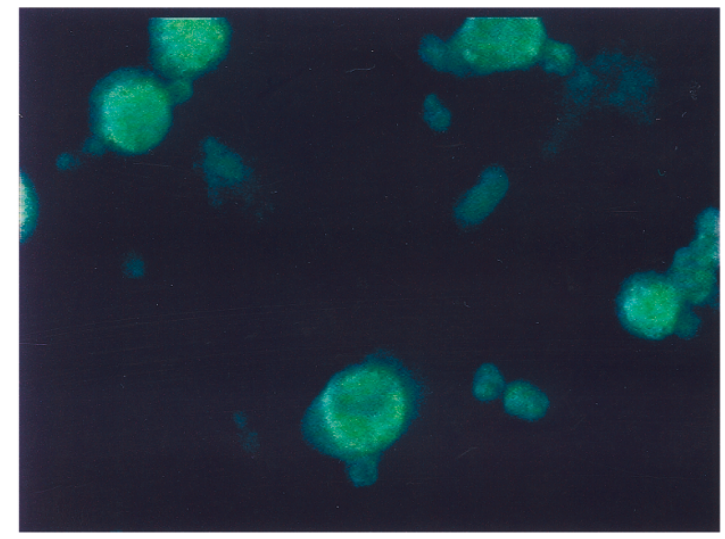

d.

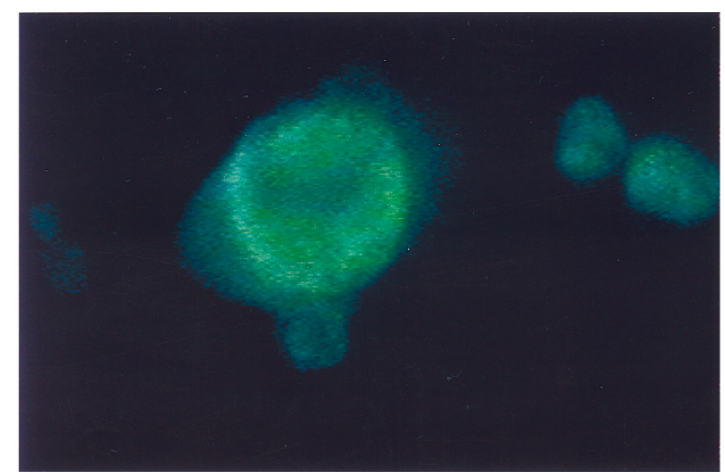

Figure 4. Photomicrographs of human DCs. DCs that were infected with rFWPV fpEFL2 at an MOI of 10 and subsequently stained for the presence of either $\beta$-gal (a: $\times 945$ magnification; b: $\times 1890$ magnification) or CD83 (c: $\times 945$ magnification; d: $\times 1890$ magnification) are shown.

recombinant poxviruses using late promoters occurs because only early promoters are functional in the target cells (DCs) in which intracellular Ag production is required to initiate the T-cell response. This also suggests an explanation for the somewhat surprising high efficacy of avipoxviruses as immunogens, ${ }^{3-35}$ because both they and the VV are rendered replication-defective in the prime APCs.

The use of recombinant poxviruses as vectors for $\mathrm{Ag}$ genes may provide some advantages over the use of single-peptide CTL epitopes to pulse DCs with Ag. The latter approach requires in-depth knowledge of the MHC restriction of the target Ag peptides. This entails extensive CTL epitope mapping and the selection of an appropriate combination of peptides for each individual patient. Moreover, immunization with single peptides means that the CTL precursor frequency may be much lower than in immunization with full-length $\mathrm{Ag}$ molecules. There is evidence that additional stimulation of $\mathrm{CD}^{+}{ }^{+}$helper responses by DC is required for effective CTL generation. ${ }^{52-54}$ When using single peptide epitopes for CTL generation, it is possible that the helper response is provided by BSA from FCS in the cultures. ${ }^{54-56}$ In a human therapeutic context, heterolo- gous sera proteins would not be present during culture, because of safety considerations. Therefore, the use of peptide-pulsed DCs in the human system would require mixtures of appropriate CTL and helper epitope peptides.

The use of whole-protein Ag-pulsed DCs may help solve this problem, because it is now clear that DCs can present exogenous soluble Ag through both MHC class I and class II pathways. ${ }^{57}$ However, delivery to the MHC class I compartment of epitopes from whole-protein Ags may be a limiting factor, with endogenous synthesis being far more efficient. ${ }^{21,52}$ The endogenous synthesis of Ag from genes transferred to human DCs via transfection or retroviral vectors may offer an advantage, but these vectors can suffer from low efficiencies of gene transfer, particularly in nonproliferating cells. The high DC transduction efficiencies, high capacity for recombinant sequences, and potential safety characteristics shown by rFWPV vectors makes them strong candidates for use in the development of DC-based immunotherapies. We are concentrating our attention on human papillomavirus and cancer of the cervix, a system in which the oncoproteins E6 and E7 are candidate tumor Ags for targeted immunotherapy. 


\section{ACKNOWLEDGMENTS}

We thank Erica de Winter and Nydia Testa for helpful comments on the manuscript. This work was supported by grants from the Cancer Research Campaign (to M.B., J.R.A., and S.N.S.), the Leukaemia Research Fund (to D.H.D.), the Medical Research Council (to D.H.D. and G.B.), and the Elimination of Leukaemia Fund (to S.H. and G.M.).

\section{REFERENCES}

1. Hart DNJ. Dendritic cells: unique leukocyte populations which control the primary immune response. Blood. 1997; 90:3245-3287.

2. Grabbe S, Beissert S, Schwartz T, Granstein RD. Dendritic cells as initiators of tumour immune response: a possible strategy for immunotherapy? Immunol Today. 1995;16:117-121.

3. Zhou LJ, Tedder TF. Human blood dendritic cells selectively express CD83, a member of the Ig superfamily. J Immunol. 1995;154:3821-3835.

4. Romani N, Gruner S, Brang D, et al. Proliferating dendritic cell progenitors in human blood. J Exp Med. 1994; 180:83-93.

5. Bernhard H, Disis ML, Heimfeld S, Hand S, Gralow JR, Cheever MA. Generation of immunostimulatory dendritic cells from human $\mathrm{CD} 34^{+}$haematopoietic progenitor cells of the bone marrow and peripheral blood. Cancer Res. 1995;55:1099-1104.

6. Caux C, Dezutter-Dambuyant C, Schmitt D, Banchereau J. GM-CSF and TNF- $\alpha$ cooperate in the generation of dendritic Langerhans cells. Nature. 1992;360:258-261.

7. Celluzzi CM, Mayordomo JI, Storkus WJ, Lotze MT, Falo LD, Jr. Peptide-pulsed dendritic cells induce antigenspecific CTL-mediated protective tumour immunity. J Exp Med. 1996;183:283-287.

8. Paglia P, Chiodoni C, Rodolfo M, Colombo MP. Murine dendritic cells loaded in vitro with soluble protein prime cytotoxic T lymphocytes against tumour antigen in vivo. $J$ Exp Med. 1996;183:317-322.

9. Murphy G, Tjoa B, Ragde H, Kenny G, Boynton A. Phase I clinical trial: T-cell therapy for prostate cancer using autologous dendritic cells pulsed with HLA-A0201-specific peptides from prostate-specific membrane antigen. Prostate. 1996;29:371-380.

10. Flamand V, Sornasse T, Thielemans K, et al. Murine dendritic cells pulsed in vitro with tumour antigen induce tumour resistance in vivo. Eur J Immunol. 1994;24:605610.

11. Porgador A, Gilboa E. Bone marrow-generated dendritic cells pulsed with a class I-restricted peptide are potent inducers of cytotoxic T lymphocytes. J Exp Med. 1995;182: 255-260.

12. Hsu FJ, Benike C, Fagnoni F, et al. Vaccination of patients with B-cell lymphoma using autologous antigen-pulsed dendritic cells. Nat Med. 1996;2:52-58.

13. Ossevoort MA, Feltkamp MC, van Veen KJ, Melief CJ, Kast WM. Dendritic cells as carriers for a cytotoxic T-lymphocyte epitope-based peptide vaccine in protection against a human papillomavirus type 16-induced tumour. J Immunother Emphasis Tumor Immunol. 1995;18:86-94.

14. Mannering SI, McKenzie JL, Fearnley DB, Hart DN. HLA-DR1-restricted bcr-abl (b3a2)-specific CD4 ${ }^{+}$T lymphocytes respond to dendritic cells pulsed with b3a2 peptide and antigen-presenting cells exposed to b3a2 containing cell lysates. Blood. 1997;90:290-297.

15. Tsai V, Southwood S, Sidney J, et al. Identification of subdominant CTL epitopes of the GP100 melanomaassociated tumor antigen by primary in vitro immunization with peptide-pulsed dendritic cells. J Immunol. 1997;158: 1796-1802.

16. Bakker AB, Marland G, de Boer AJ, et al. Generation of antimelanoma cytotoxic $\mathrm{T}$ lymphocytes from healthy donors after presentation of melanoma-associated antigenderived epitopes by dendritic cells in vitro. Cancer Res. 1995;55:5330-5334.

17. Alijagic S, Moller P, Artuc M, Jurgovsky K, Czarnetzki BM, Schadendorf D. Dendritic cells generated from peripheral blood transfected with human tyrosinase induce specific T cell activation. Eur J Immunol. 1995;25:31003107.

18. Arthur JF, Butterfield LH, Roth MD, et al. A comparison of gene transfer methods in human dendritic cells. Cancer Gene Ther. 1996;4:17-25.

19. Aicher A, Westermann J, Cayeux S, et al. Successful retroviral mediated transduction of a reporter gene in human dendritic cells: feasibility of therapy with genemodified antigen-presenting cells. Exp Hematol. 1997;25: 39-44.

20. Henderson RA, Nimgaonkar MT, Watkins SC, Robbins PD, Ball ED, Finn OJ. Human dendritic cells genetically engineered to express high levels of the human epithelial tumour antigen mucin (MUC-1). Cancer Res. 1996;56: 3763-3770.

21. Brossart P, Goldrath AW, Butz EA, Martin S, Bevan MJ. Virus-mediated delivery of antigenic epitopes into dendritic cells as a means to induce CTL. J Immunol. 1997; 158:3270-3276.

22. Smith GL, Binns MM, eds. Recombinant Poxviruses. Boca Raton, FL: CRC Press; 1992.

23. Bennink JR, Yewdell JW. Recombinant vaccinia viruses as vectors for studying T lymphocyte specificity and function. Curr Top Microbiol Immunol. 1990;163:153-184.

24. Borysiewicz LK, Fiander A, Nimako M, et al. A recombinant vaccinia virus encoding human papillomavirus type 16 and 18, E6 and E7 proteins as immunotherapy for cervical cancer. Lancet. 1996;347:1523-1527.

25. Tsang KY, Zaremba S, Nieroda CA, Zhu MZ, Hamilton JM, Schlom J. Generation of human cytotoxic $\mathrm{T}$ cells specific for human carcinoembryonic antigen epitopes from patients immunized with recombinant vaccinia CEA vaccine. J Natl Cancer Inst. 1995;87:982-990.

26. Behbehani AM. The smallpox story: life and death of an old disease. Microbiol Rev. 1983;47:455-509.

27. Redfield RR, Wright DC, James WD, Jones TS, Brown C, Burke DS. Disseminated vaccinia in a military recruit with human immunodeficiency virus (HIV) disease. $N$ Engl J Med. 1987;316:673-676.

28. Picard O, Lebas J, Imbert JC, Bigel P, Zagury D. Complication of intramuscular/subcutaneous immune therapy in severely immune-compromised individuals. J Acquir Immune Defic Syndr. 1991;4:641-643.

29. Cooney EL, Collier AC, Greenberg PD, et al. Safety of and immunological response to a recombinant vaccinia virus vaccine expressing HIV envelope glycoprotein. Lancet. 1991;337:567-572.

30. Andrew ME, Coupar BEH, Boyle DB. Immunogenicity and antigen presentation. In: Smith GL, Binns MM, eds. Recombinant Poxviruses. Boca Raton, FL: CRC Press; 1992:207-234. 
31. Somogyi P, Frazier J, Skinner MA. Fowlpox virus host range restriction: gene expression, DNA replication, and morphogenesis in nonpermissive mammalian cells. Virology. 1993;197:439-444.

32. Taylor J, Paoletti E. Fowlpoxvirus as a vector for non-avian species. Vaccine. 1988;6:466-468.

33. Fries LF, Tartaglia J, Taylor J, et al. Human safety and immunogenicity of a canarypox-rabies glycoprotein recombinant vaccine: an alternative poxvirus vector system. Vaccine. 1996;14:428-434.

34. Pialoux G, Excler JL, Riviere Y, et al. A prime-boost approach to HIV preventive vaccine using a recombinant canarypox virus expressing glycoprotein 160 (MN) followed by a recombinant glycoprotein 160 (MN/LAI): the AGIS Group, and l'Agence Nationale de Recherche sur le SIDA [published erratum appears in AIDS Res Hum Retroviruses. 1995;11:875]. AIDS Res Hum Retroviruses. 1995;11:373-381.

35. Tubiana R, Gomard E, Fleury H, et al. Vaccine therapy in early HIV-1 infection using a recombinant canarypox virus expressing gp160MN (ALVAC-HIV): a double-blind controlled randomized study of safety and immunogenicity. AIDS. 1997;11:819-820.

36. Wang M, Bronte V, Chen PW, et al. Active immunotherapy of cancer with a nonreplicating recombinant fowlpox virus encoding a model tumor-associated antigen. J Immunol. 1995;154:4685-4692.

37. Toso JF, Oei C, Oshidari F, et al. MAGE-1-specific precursor cytotoxic T-lymphocytes present among tumourinfiltrating lymphocytes from a patient with breast cancer: characterisation and antigen-specific activation. Cancer Res. 1996;56:16-20.

38. Tarpey I, Stacey S, Hickling J, et al. Human cytotoxic T lymphocytes stimulated by endogenously processed human papillomavirus type $11 \mathrm{E} 7$ recognize a peptide containing a HLA-A2 (A*0201) motif. Immunology. 1994;81:222-227.

39. Binns MM, Stenzler L, Tomley FM, Campbell J, Boursnell ME. Identification by a random sequencing strategy of the fowlpoxvirus DNA polymerase gene, its nucleotide sequence, and comparison with other viral DNA polymerases. Nucleic Acids Res. 1987;15:6563-6573.

40. Moscovici C, Moscovici MG, Jimenez H. Continuous tissue culture cell lines derived from chemically induced tumours of Japanese quail. Cell. 1977;11:95-103.

41. Boursnell ME, Green PF, Campbell JI, et al. Insertion of the fusion gene from Newcastle disease virus into a non-essential region in the terminal repeats of fowlpox virus and demonstration of protective immunity induced by the recombinant. J Gen Virol. 1990;71:621-628.

42. Qingzhong Y, Barrett T, Brown TD, et al. Protection against turkey rhinotracheitis pneumovirus (TRTV) induced by a fowlpox virus recombinant expressing the TRTV fusion glycoprotein (F). Vaccine. 1994;12:569-573.

43. Binns MM, Boursnell MEG, Tomley FM, Campbell JIA. Analysis of the fowlpox virus gene encoding the $4 \mathrm{~b}$ core polypeptide and demonstration that it possesses efficient promoter sequences. Virology. 1989;170:289-291.

44. Smith GL, Mackett M. The design, construction, and use of vaccinia virus recombinants. In: Smith GL, Binns MM, eds. Recombinant Poxviruses. Boca Raton, FL: CRC Press; 1992;1992:81-122.

45. Li J, Bowen G, Murphy JJ, Davies DH, Hollingsworth SJ, Mufti G. Induction of human T cell responses to tumourassociated neoantigens and virus antigens using cultured dendritic cells. Biochem Soc Trans. 1997;25:204S, 1997.

46. Bronte V, Carroll MW, Goletz TJ, et al. Antigen expression by dendritic cells correlates with the therapeutic effectiveness of a model recombinant poxvirus tumour vaccine. Proc Natl Acad Sci USA. 1997;94:3183-3188.

47. Broder CC, Kennedy PE, Michaels F, Berger EA. Expression of foreign genes in cultured human primary macrophages using recombinant vaccinia virus vectors. Gene. 1994;142:167-174.

48. Coupar BE, Andrew ME, Boyle DB. A general method for the construction of recombinant vaccinia viruses expressing multiple foreign genes. Gene. 1988;68:1-10.

49. Wachsman M, Aurelian L, Smith CC, Perkus ME, Paoletti E. Regulation of expression of herpes simplex virus (HSV) glycoprotein D in vaccinia recombinants affects their ability to protect from cutaneous HSV-2 disease. J Infect Dis. 1989; 159:625-634.

50. Smith GL, Howard ST, Chan YS. Vaccinia virus encodes a family of genes with homology to serine proteinase inhibitors. J Gen Virol. 1989;70:2333-2343.

51. Townsend A, Bastin J, Gould K, et al. Defective presentation to class I-restricted cytotoxic $\mathrm{T}$ lymphocytes in vaccinia-infected cells is overcome by enhanced degradation of antigen. J Exp Med. 1988;168:1211-1224.

52. Nonacs R, Humborg C, Tam JP, Steinman RM. Mechanisms of mouse spleen dendritic cell function in the generation of influenza-specific, cytolytic T lymphocytes. $J$ Exp Med. 1992;176:519-529.

53. Zitvogel L, Mayordomo JI, Tjandrawan T, et al. Therapy of murine tumours with peptide-pulsed dendritic cells: dependence on T cells, B7 costimulation, and T helper cell 1-associated cytokines. J Exp Med. 1996;183:87-97.

54. Porgador A, Snyder D, Gilboa E. Induction of antitumor immunity using bone marrow-generated dendritic cells. J Immunol. 1996;156:2918-2926.

55. Inaba K, Inaba M, Naito M, Steinman RM. Dendritic cell progenitors phagocytose particulates, including bacillus Calmette-Guerin organisms, and sensitize mice to mycobacterial antigens in vivo. J Exp Med. 1993;178:479-488.

56. Young JW, Inaba K. Dendritic cells as adjuvants for class I major histocompatibility complex-restricted antitumour immunity. J Exp Med. 1996;183:7-11.

57. Norbury CC, Chambers BJ, Prescott AR, Ljunggren H, Watts C. Constitutive macropinocytosis allows TAP-dependent major histocompatibility complex class I presentation of exogenous soluble antigen by bone marrowderived dendritic cells. Eur J Immunol. 1997;27:280-288. 